\title{
Ketoprofen Loaded Poly(D,L-lactic acid) Nanospheres for Potential Transdermal/Dermal Application: Preparation and Physical Characterization
}

\author{
S. T. VUČEN ${ }^{1}$, G. VULETA ${ }^{2}$, N. IGNJATOVIĆ ${ }^{3}$, D. USKOKOVIĆ ${ }^{3}$ \\ ${ }^{1}$ Faculty of Medicine, Department of Pharmacy, University of Banja Luka, Bosnia and Herzegovina \\ ${ }^{2}$ Department of the pharmaceutical technology and cosmetology, Faculty of Pharmacy, University of \\ Belgrade, Serbia \\ ${ }^{3}$ Institute of technical sciences of the Serbian Academy of Sciences and Arts, Belgrade, Serbia \\ E-mail: sonjatorbica@gmail.com (S. T. Vučen)
}

Sci Pharm. 2010; 78: 680

doi:10.3797/scipharm.cespt.8.PNM10

\begin{abstract}
Ketoprofen is a potent non-steroidal anti-inflammatory drug and an excellent candidate for transdermal/dermal delivery because of its adverse side effects and short elimination half-time after oral administration [1,2]. It is previously reported that drug loaded nanoparticles may provide a number of advantages compared to free drug such as increasing of bioavailability and drug skin penetration, ensuring controlled drug delivery, delayed and prolonged drug action in the application site $[3,4]$. Therefore, the aim of our work was to prepare poly-D,L-lactide nanospheres of ketoprofen by modified precipitation method and to characterize them $[5,6]$. The size and morphology of the obtained particles have been determined by field-emission scanning electron microscopy (FESEM) and laser light diffraction. Span value and mean diameter were about 1,3 and $65 \mathrm{~nm}$, respectively. The encapsulation of ketoprofen into the PDLLA nanospheres was confirmed by X-ray diffraction (XRD) and infrared spectroscopy (FT-IR). Nanoparticles of ketoprofen were obtained with high encapsulation efficiency.
\end{abstract}

[1] Fujii M, Hori N, Shiozawa K, Wakabayashi K, Kawahara E, Matsumoto M. Effect of fatty acid Esters on permeation of ketoprofen through hairless rat skin. Int J Pharm. 2000; 205: 117-125. doi:10.1016/S0378-5173(00)00496-8

[2] Kim B.S, Won M, Yang, Lee K.M, Kim C.S. In Vitro Permeation Studies of Nanoemulsions Containing Ketoprofen as a Model Drug. Drug Deliv. 2008; 15: 465-469. doi:10.1080/10717540802328599

[3] Luengo J, Weiss B, Schneider M, Ehlers A, Stracke F, König K, Kostka K.H, Lehr C.M, Schaefer U.F. Influence of nanoincapsulation on human skin transport of flufenamic acid. Skin Pharmacol Physiol. 2006; 19: 190-197. doi:10.1159/000093114

[4] Rancan F, Papakostas D, Hadam S, Hackbarth S, Delair T, Primard C, Verrier B, Sterry W, Peytavi U.B, Vogt A. Investigation of Polylactic Acid (PLA) Nanoparticles as Drug Delivery Systems for Local Dermatotherapy. Pharm Res. 2009; 26: 2027-2036. doi:10.1007/s11095-009-9919-x

[5] Stevanović M, Ignjatović N, Jordović B, Uskoković D. Stereological analysis of the poly(D, L-lactide-coglycolide) submicron sphere prepared by solvent/non-solvent chemical methods and centrifugal processing. J Mater Sci: Mater Med. 2007; 18: 1339-1344. doi:10.1007/s10856-007-0156-8

[6] Jovanović I, Jordović B, PetkovićM, Ignjatović N, Uskoković D. Preparation of smallest microparticles of poly-D, L-lactide by modified precipitation method: Influence of the process parameters. Microsc Res Tech. 2008; 71: 86-92. doi:10.1002/jemt.20529 